\title{
Health inequalities affect the health of all
}

'We must never forget: evidence has great strategic and persuasive power at the policy level.' (Director-General of the World Health Organization, 2007)

The runaway publishing success of The Spirit Level by Wilkinson and Pickett has put health inequalities on everyone's lips. ${ }^{1,2}$ Using the evidence, based on decades of research, they remind us that the causes of most health inequalities in developed countries are rooted in the structure of society and particularly in income inequalities. Using data from 23 of the richest countries, and a separate analysis for the 50 states of North America, they illustrate the social gradient in lifeexpectancy, and physical health, along with other factors on the index of health and social problems, such as educational performance, levels of trust within local communities, imprisonment rates, teenage births, and homicides.

\section{THE MORTALITY GRADIENT}

Every country and North American state has a social gradient for each of these factors. But the book's message is that the level of income inequalities within developed countries will determine where a country falls on the international gradient. Hence the UK, with high current levels of income inequality, will fall low on the international gradient for many of the societal factors that predict premature mortality and chronic ill health.

Combining this international message with that from the recent Marmot Review of health inequalities in England makes for serious reflection. Marmot confirms the continuing mortality gradient of 7 years between the richest and the poorest groups in society, and the equally stark gap of 17 years of disability-free life expectancy when compared across the gradient of neighbourhood incomes in England. ${ }^{3}$

The emphasis on the slope of the gradient is key. The steeper the inequality gradient the less sense there is in just attending to those at the bottom. The burden of inequalities is not the sole experience of the poorest in society. The effects of inequality are felt, although to a lesser degree, by everyone below those at the top of the slope. The concept of 'proportionate universalism' is an example of shifting the position of the mean value: that is, shifting the entire population towards better health. Action to reduce the slope of the gradient means that the effect of the intervention is felt throughout the population.

\section{THE ROLE OF GENERAL PRACTICE}

Perhaps one of the problems of this emerging narrative, which describes and explains health inequalities, is how small the effect of traditional health services whether in hospitals or in primary care settings - is on reducing the gradient. Clearly this is in contrast to the situation in less developed countries where improving access to effective health services remains a priority. ${ }^{4}$ It might be thought that the only possible response to this is a political change of heart to favour income redistribution, and that as doctors particularly in primary care settings - we have a marginal role to play in creating solutions. But this is not so; our roles as witnesses, advocates and actors are an essential part of our task. ${ }^{5}$

The role of GPs as witnesses to what is happening to the individuals and populations we look after has always been significant. As witnesses we both contribute to the human story and systematise the available data to understand the effect of inequalities. Providing a sense of the lived experience is important both for explaining other data and to support advocacy for change. Research into unemployment and health, such as that by Beale and Nethercott, illustrates the importance of uncovering and documenting the effect of social policy on individuals. ${ }^{6}$ Other examples include unmasking some of the differences in the burden of disease, and inequalities in the use of health services by minority ethnic groups. $^{7}$

As actors in the delivery of health services, we are enjoined to have a culture of clinical excellence. To reverse the inverse care law we need to 'match the greatest need with the highest standard of care'. ${ }^{8}$ The Quality and Outcomes Framework (QOF), the greatest experiment in pay for performance in Europe, has been surprisingly successful at improving the measured, technical aspects of the clinical domains. Research has illustrated that practices in deprived localities improved performance to the level of their peers in the least deprived areas over a period of only 3 years. ${ }^{9-11}$ Similarly small practices (which previously showed the greatest quality variation) reduced this clinical practice variation the most under the yoke of the QOF.12 This has occurred despite the continuing 'inverse funding' regime.

Implementing effective preventive health care in deprived areas requires greater effort, resource, and support from equally overstretched local agencies. The burden on healthcare providers, and their ability to flourish and provide high quality services in such environments, remains underresearched..$^{13}$ It is also noteworthy that the lack of data on ethnicity and social deprivation limits the value of information from the QOF as a tool to contribute towards a health equity surveillance framework for general practice.

The enduring British passion for the NHS can be understood, in the context of health inequalities, as standing for one of the few institutions where people's needs are met regardless of their position in society. This fosters a continuing sense of community and social cohesion in an environment which is often seen as increasingly hostile to the poor. This requires us to be assertive in our role as advocates for our populations, and GPs have a unique opportunity over the next few years. 


\section{PARTNERSHIP OPPORTUNITIES}

It is time to promote the integration of personal health care alongside public health to promote equity and social cohesion. As we look beyond the individual in our attempts to commission health service for populations, we will see opportunities for partnerships in delivering community prescriptions as part of the public health function. In London, perhaps the best known example of this is the Bromley by Bow Centre (http://www.bbbc.org.uk) which includes education, arts, and benefits advice alongside traditional health services. This is but one of many examples of community-oriented primary care which combines personal health care with community-orientated public health using a 'community diagnosis' to introduce change. ${ }^{14}$

The emerging GP commissioning consortia present new opportunities for positive action, marred by the blight and instability of repetitive NHS reform and the inevitable pain of a shrinking welfare budget. We need to heed the warning that the inverse care law 'operates more completely where medical care is most exposed to market forces, and less so where such exposure is reduced'. ${ }^{8}$ The emphasis in the White Paper Equity and Excellence: Liberating the $N H S^{15}$ continues an agenda of expanding the market in health services, which may work against the gradient of equity.

Increasing health inequality and income inequality is not an inevitability. Shifting the research agenda towards implementation strategies for improving the social determinants of health will arguably bring larger health improvements than expanding the biomedical portfolio. But it will also require a determination by doctors as researchers, advocates, and citizens, along with politicians, to set a different course.

\section{Sally Hull,}

GP, Tower Hamlets, London, and Clinical Senior Lecturer, Institute of Health Sciences, Queen Mary University of London.

\section{Provenance}

Commissioned; not peer reviewed.

\section{REFERENCES}

1. Wilkinson R, Pickett K. The spirit level: why more equal societies almost always do better. London: Allen Lane, 2009.

2. Booth R. The Spirit Level: how 'ideas wreckers' turned book into political punchbag. The Guardian 2010; 14 Aug. http://www.guardian.co.uk/books/2010/aug/14/thespirit-level-equality-thinktanks (accessed 11 Nov 2010).

3. Marmot M. Fair society, healthy lives. Strategic review of health inequalities in England post-2010. London: The Marmot Review, 2010. http://www.marmotreview.org/ (accessed 22 Oct 2010)

4. Commission on Social Determinants of Health. Closing the gap in a generation: health equity through action on the social determinants of health. Final Report of the Commission on Social Determinants of Health. Geneva: World Health Organization, 2008. http://whqlibdoc.who.int/publications/2008/978924156 3703_eng.pdf (accessed 22 Oct 2010).

5. Smeeth L, Heath I. Why inequalities in health matter to primary care. Br J Gen Pract 2001; 51(467): 436-437.

6. Beale N, Nethercott $S$. The health of industrial employees four years after compulsory redundancy. J R Coll Gen Pract 1987; 37(302): 390-394.

7. CEG events (Clinical Effectiveness Group). Health equity conference. Queen Mary University Innovation Centre: London, 2010. http://www.ihse.qmul.ac.uk/chs/ceg/Events/index.html (accessed 22 Oct 2010)

8. Tudor Hart J. The inverse care law. Lancet 1971; 297(7696): 405-412.

9. Campbell SM, Reeves D, Kontopantelis E, et al. Effects of pay for performance on the quality of primary care in England. N Engl J Med 2009; 361(4): 368-378.

10. Ashworth M, Kordowicz M. Quality and Outcomes Framework: time to take stock. Br J Gen Pract 2010; 60(578): 637-638.

11. Kiran T, Hutchings A, Dhalla IA, et al. The association between quality of primary care, deprivation and cardiovascular outcomes: a cross-sectional study using data from the UK Quality and Outcomes Framework. 5 Epidemiol Community Health 2010; 64(10): 927-934.

12. Doran T, Campbell S, Fullwood C, et al. Performance of small practices under the UK's Quality and Outcomes Framework. Br J Gen Pract 2010; 60(578): e335-344.

13. Wallace JE, Lemaire JB, Ghali WA. Physician wellness: a missing quality indicator. Lancet 2009; 374(9702): 1714-1721.

14. Van Wheel C, De Maeseneer J, Roberts R. Integration of personal and community health care. Lancet 2008; 372(9642): 871-872.

15. Department of Health. Equity and excellence: liberating the NHS. London: Department of Health, 2010.

DOI: 10.3399/bjgp10X544005

ADDRESS FOR CORRESPONDENCE

Sally Hull

GP, Tower Hamlets, London, and Clinical

Senior Lecturer, Institute of Health

Sciences, Queen Mary University of

London, London, E1 2AT.

E-mail: s.a.hull@qmul.ac.uk 